2 Krejs GJ, Little KH, Westergraard H, et al. Laser photocoagulation for the treatment of acute peptic-ulcer bleeding: a
randomized controlled clinical trial. N Engl f Med 1987;316: 1618-21.

3 Collins R, Langman M. Treatment with histamine $H_{2}$, antagonists in acute upper gastrointestinal tract hemorrhage: implications of randomized trials. N Engl J Med 1985;313: 660-6.

\section{Intensive care: a specialty or a branch of anaesthetics?}

SIR,-I have read the recommendations of the interfaculty collegiate liaison group on intensive therapy ${ }^{1}$ and have followed the correspondence in the $B M \mathcal{F}$ (25 April, p 1095; 30 May, p 1415) and Anaesthesia. ${ }^{2}$

From the standpoint of a consultant anaesthetist in a district general hospital with a four sessional weekly commitment to eight intensive care beds, I have several observations to make. I have, incidentally, fulfilled the recommendations of the liaison group in terms of training.

The constitution of the liaison group does not reflect the lifestyle of intensivists who work in district general hospitals. Most doctors who train for consultant posts in intensive care will work in district general hospitals and their views should be better represented in the group.

The general aim to provide modular training for doctors of any specialty in intensive care is admirable. The problems of the divisive and competitive training arrangements of the USA and Australia must be avoided. Although the liaison group goes a long way to meet this end, staging training at senior registrar level may defeat its aim. The main obstacle to a modular training scheme accessible to all specialties is the problem of transition from one specialty to another. The liaison group intensifies this by pitching the grade at senior registrar level. The programme would be better suited to registrars, who would enjoy and benefit from the variety, are adaptable, and have not finalised their career commitments. There would be valuable spin offs in other spheres of medicine common to all, such as resuscitation, which is practised appallingly by nearly all except anaesthetists.

Stoddart is correct in saying that anaesthetists are at present more suited to running intensive care units than physicians or surgeons, especially in district general hospitals. ${ }^{2}$ This does not detract from the outstanding contributions made by those from other specialties. Many anaesthetists have copious medical experience to reinforce their specialist knowiedge of anaesthesia, physiology, and pharmacology and have been aware for many years of the restrictions of specialisation and the acrimony that can arise from the self centred view. They are well suited to intensive care as either "brokers" or "shareholders" to use Dudley's analogy. ${ }^{3}$ Career physicians and surgeons would derive much from experience in anaesthesia but may be discouraged from doing so because there is no prestigious diploma to be had after a year in anaesthesia, whereas the full MRCP may be obtained by those with the determination after a year in medicine.

Running a DGH intensive care unit is physically and mentally demanding and the specialist back up of the teaching hospital may not be there-neither may the junior staff. ${ }^{4}$ Although I must count myself fortunate in having access to all the necessary specialties and to a dedicated registrar grade intensivist, I still have to roll up my sleeves and get to work. The input of many clinicians into the management of a patient has to be coordinated, the practical aspects of the work completed, and summaries written. The practical as well as the intellectual skills that make intensive care successful have to be learnt. Unfortunately it is learnt by an apprenticeship, time consuming and often antisocial in terms of domestic commitments. Senior registrars are in their 30 s by the time they complete their higher professional training. They have wives and families who would love to see them. They should be learning management skills, not the practical skills, at this stage. This type of training is surely more appropriate to registrar grades and would be more attractive to differing specialties at that level.

There is undoubtedly scope for training in intensive care at senior registrar grade but it should provide opportunities for research and development of the specialty. ${ }^{5}$ But the basic skills and groundwork are best learnt at registrar grade. Here, cross fertilisation of ideas and cooperation of the specialties in the intensive care unit can be achieved. This in itself would make the unit a less forbidding place for junior staff than it is at present.

The aim of the liaison group is to impove the care of critically ill patients in Britain. We must be sure that the training scheme adopted achieves these aims rather than simply trains people.

Royal Cornwall Hospital,

GILES MORGAN

Truro TRI 3LJ

1 Inter-Faculty Collegiate Liaison Group on Intensive Therapy. Recommendations for the training of consultants with a specia interest in intensive care. Care of the Critically Ill 1985;1:4-5. 2 Stoddart JC. A career post-with intensive therapy? Anuesthesia 1986;41:1181-3.

3 Dudley HAF. Intensive care: a specialty or a branch of anaesthetics? BrMed f 1987;294:459-60.

Browne DRG. A way forward for intensive care. Anaesthesia 1987;42:550-1.

Hinds CJ. A way forward for intensive care. Anaesthesia 1987; 42:551.

\section{Child abuse or copper deficiency?}

SIR,-I was glad to see the beginnings of a debate on the possible risk of confusion between infantile copper deficiency and child abuse, as highlighted by Dr Stephen Chapman (30 May, p 1370). Over the past 10 years I have seen, both in England and abroad, 35 infants who seemed to have had a temporary, severe osteogenesis imperfecta-like disorder. In most cases the initial diagnosis was child abuse, but in three the initial diagnosis was osteogenesis imperfecta because the fractures occurred in hospital. In each case where the patients were thought to be victims of child abuse there was remarkably little clinical evidence of the trauma that would have been needed had the bones been normal. In five of these cases further fractures, generally rib fractures, occurred in hospital. In almost all cases most of the fractures were found by radiology and had not been suspected clinically.

Bone density was usually normal, as far as may be judged by ordinary radiographs (this assessment, however, must be taken with caution'). The combination of reduced bone strength and maintained mineral content makes it likely that the disorder, like osteogenesis imperfecta and experimental lathyrism,$^{23}$ represents a collagen defect. Apart from long bone and rib fractures, many patients had metaphyseal fractures or fracture like appearances. Many patients also had extraskeletal abnormalities, such as petechiae, hernias, anaemia (generally microcytic), or neutropenia. Some had gastrointestinal symptoms, such as vomiting (often projectile) or intermittent diarrhoea. These features suggest that the most probable cause of such a temporary collagen defect is copper deficiency, which may be transient but leaves behind bone of abnormal strength for some months. It is striking that in all but two cases the fractures were discovered within the first six months of life.
What could cause such a deficiency? Risk factors seem to include preterm birth and multiple pregnancy (11 of my cases were twins), both of which are recognised risk factors in reports of copper deficiency. Preterm infants often have a transient copper deficiency in early infancy. ${ }^{4}$ The disorder occurred in only one breast fed infant, and formula feeds may play a part in its development.

Most of these cases were investigated many months after the fractures had occurred, and in only one case was a low serum copper concentration found, at 6 weeks of age. In any case, serum copper concentration may be a poor measure of tissue copper stores. ${ }^{5}$ Whether all the cases of this syndrome represent copper deficiency or result from some other temporary defect of collagen maturation requires further investigation. In the mean time we need to be cautious in identifying child abuse without any corroborative social evidence, as this disorder, like osteogenesis imperfecta and rickets, ${ }^{67}$ may be mistaken for child abuse, with devastating effects on a family.

Ninewells Hospital and Medical School,

C R PATERSON Dundee DD1 9SY

1 Doyle FH, Gutteridge DH, Joplin GF, Fraser R. An assessmen of radiological criteria used in the study of spinal osteoporosis. of radiological criteria used in

2 Paterson CR, McAllion SJ, Shaw JW. Clinical and radiological features of osteogenesis imperfecta type IVA. Acta Paediatr Scand (in press).

3 Bell GH, Dunbar O, Gillespie JA, Iball J, Oliver J. Effect of sweet pea poisoning on strength of bone and skin. $\mathcal{J}$ Physiol 1957;139:17-8.

4 Manser JI, Crawford CS, Tyrala EE, Brodsky NL, Grover WD Serum copper concentrations in sick and well preterm infants. J Pediatr 1980;97:795-9.

5 Mills CF. Some outstanding problems in the detection of trace element deficiency diseases. Philos Trans $R$ Soc Lond [Biol] 1981;294:199-213.

6 Paterson CR. Osteogenesis imperfecta in the differential diagnosis of child abuse. Child Abuse and Neglect 1977;1:449-52.

7 Paterson CR. Vitamin D deficiency rickets simulating child abuse. F Pediatr Orthop 1981;1:423-5.

AUTHOR'S REPLY,-I am glad to see that Dr

Paterson welcomes the beginnings of a debate in the medical press, as up to this time the possible role of copper deficiency as a cause of fractures in cases of suspected child abuse has been raised by him only in the courts. Dr Paterson now believes that he has personally seen 35 cases with fractures. This is a remarkable number in view of the fact that the total number of reported cases in the world is only about 15 .

Dr Paterson cannot reconcile the absence of external signs of trauma with normal bones. All of us who deal with acute trauma in normal children, however, realise that this does occur. The incidence of occult fractures in non-accidental injury is high, and there are several reasons for this. Many are due to twisting or pulling forces applied at a site remote from the actual fracture, and if the periosteum remains intact there will be no bleeding from the fractured bone into the soft tissues. The fracture may be old, and thus the external signs (if there were any) would have resolved. Local soft tissue injury may be reduced if the child is injured when clothed. If there is a collagen disorder that increases fragility of the blood vessels then bruising, even without fractures, should be even more common.

If, then, the conclusion of reduced bone strength is untenable normal bone density is further evidence that is much more likely to equate with normal bones than with a collagen defect. All the patients in published cases of copper deficiency with fractures have had obviously osteoporotic bones, and in many this has been severe. Fractures have probably been secondary to osteoporosis. A failure to appreciate that intra-articular metaphyseal fractures may heal without callus formation leads Dr Paterson to deny that they are fractures 